\title{
A Mystery in the Weird Clouds of Venus
}

\author{
Kristel Tjandra (D) \\ https://doi.org/10.54739/mbxu
}

ast week the discovery of phosphine on Venus sparked conversations among scientists and astronomical enthusiasts. What is the excitement really about and what could it mean for us? We were lucky to interview one of the authors, Paul Rimmer, on the Peaceful Science forum. As Rimmer puts it, "The detection of phosphine itself (is exciting). Whatever its cause...it just shouldn't be there, and the mystery is compelling."

This is a fascinating discovery, but the finding is not definitive. The unexpected detection of phosphine gas is a mystery that draws our attention to Venus.

\section{The Truth and fiction of Venus}

Venus is our nearest and most Earth-like planetary neighbor. In recent decades, Mars captured our imagination, with several rovers and a possible manned mission in the works. But Venus has its own interesting history.

At first, we thought it was a planet with a giant ocean, or large swamp, perhaps a grand paradise. Decades before space travel, the 1903 Nobel Prize winner, Svante Arrhenius, described Venus in his cosmological book, The Destinies of the Stars (1918), as a largely habitable planet with temperature that may support "luxuriant vegetation." He proposed that "only low forms of life (may be found there), mostly no doubt belonging to the vegetable kingdom." These images of Venus are visible in science fiction, like C.S. Lewis's Perelandra, and Olaf Stapledon Last and First Men. They depict Venus as this paradise-like escapade destination from Earth.

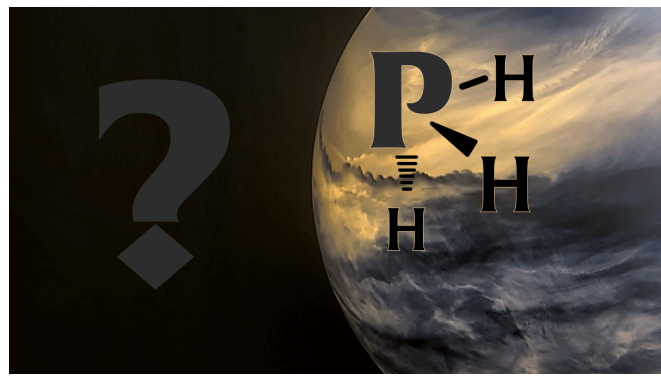

The truth ended up far stranger than the fiction. In 1967, the Venera 4 and Mariner 5 probes finally got a good look, showing that Venus was nothing like what we imagined. It was a planet of acid clouds. It may have had an ocean in the past, but now its atmosphere is permanently full of twisting and swirling clouds. If NASA ever tries to send astronauts to Venus, they might float in blimps above the clouds. The surface of the planet though, due to the thick atmosphere, is among the hottest and most crushing places in the solar system.

\section{What's so Exciting About Phosphine?}

So, what is so exciting about finding phosphine? On Venus, phosphine might be a sign of microbial life floating up in its

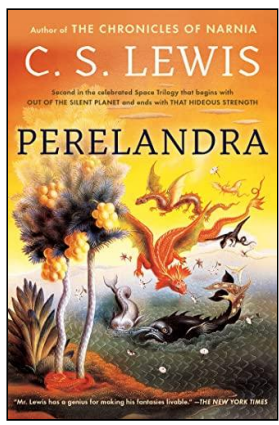

In C.S. Lewis's depiction of Venus in the Space Trilogy, "The planet is covered, so far as Ransom can at first see, by a sweet-water ocean, which is dotted with floating rafts of vegetation." clouds. We've seen phosphine on Jupiter and Saturn, but on those planets phosphine was likely produced by non-life processes on the planets. Phosphine is the fully reduced version of the element phosphorus, with three hydrogens attached like three legs. Paradoxically, it is toxic to humans, and any life that depends on oxygen. But not all life requires oxygen, and we know that anaerobic life often produces phosphine.

From a scientific point-of-view, this is a discovery that needs further confirmation. One possible contention would be the possibility of detecting signals of other unknown compounds that are similar to phosphine. In fact, in an interview with National Geographic, ALMA Observatory scientist, Dr. John Carpenter expressed skepticism for the "faint signal" and lack of "multiple fingerprints" to support the identification of the molecule. Similar caution was expressed by Dr. Paul B. Rimmer, who co-authored the original Nature Astronomy article.

As Dr. Rimmer says, “ There's too much we just don't know”.

There are indeed many questions here. As Swamidass, puts it in the Panda's Thumb,

Was the phosphine, in the end, produced by something other than life? Is there any combination of geological and chemical processes, perhaps with input from meteorites, that could produce phosphine on an ongoing basis? 
Or is this really life? Did that life first arise when Venus had oceans, and then move to the skies? Was life seeded in Venus by probes in the 1970s and 80s sent from Earth? How similar or different will these microbes be than those found on Earth?

Or was it the most mundane of all options? Could there be an error in the detection? Is there another chemical that absorbs light at the same wavelength? Was there some other technical loophole that misleads us here?

Questions like these are surely going to shape research going forward. Perhaps we have put too much focus on Mars, to the detriment of exploring other worlds. What will a mission to Venus tell us about these questions? Would it be possible to return samples of those sulfuric clouds to Earth?

\section{The Meaning of Venus}

Returning our attention to Venus has other lessons for us. "Venus used to be as fit for life as earth," with oceans and an environment

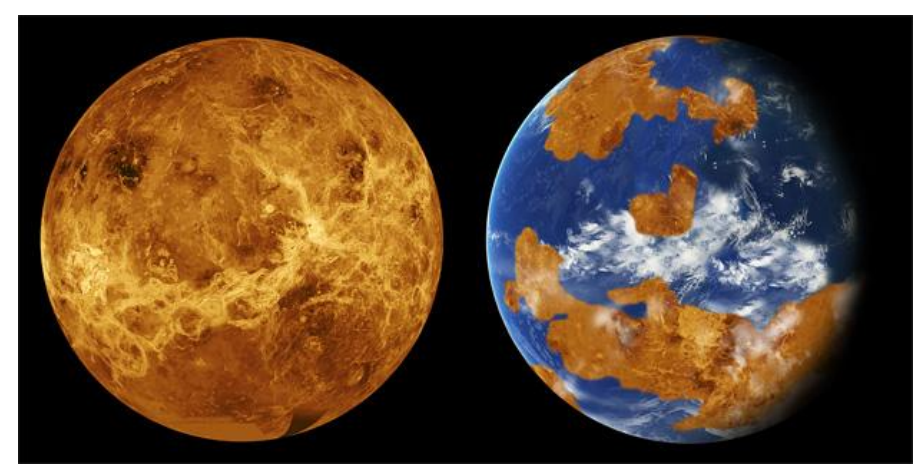

Image of a habitable Venus in the past.

\section{References}

https://discourse.peacefulscience.org/t/_/11729

https://www.wired.com/story/dr-phosphine-and-the-possibility-of-lifeon-venus

https://pandasthumb.org/archives/2020/09/mystery-phosphinevenus.html\#more

https://www.gutenberg.org/files/58222/58222-h/ 58222-h.htm\#CHAPTER_I

https://en.wikipedia.org/wiki/Venus_in_fiction

https://amazon.com/dp/074323491X/

https://en.wikipedia.org/wiki/Perelandra

https://en.wikipedia.org/wiki/Raft

https://en.wikipedia.org/wiki/Venera_4

https://en.wikipedia.org/wiki/Mariner_5

https://www.scientificamerican.com/article/venus-ussr-1967-mission

https://astronomy.com/news/2020/04/why-are-venus-clouds-so-weird much like ours. This should remind us, Dr. Grinspoon has said, to "be good stewards of Earth". He notes, "we will never fully understand our planet, or our own role in its evolution, in a vacuum. We need a point of comparison. Venus provides one. It is a natural laboratory to test our models and hone our understanding of extreme climate change."

Astrophysicist, Dr. Paul M. Sutter sees Venus as a dire warning for us: "Venus became a runaway greenhouse with all the water dumped into the atmosphere trapping as much heat as possible, with the surface temperatures continuing to skyrocket," he said, "And here's the worst part about the story of Earth's twisted sister. This is our fate, too." Dr. Carolin Crawford from the University of Cambridge has explained how Earth and Venus share the same origin, yet different outcomes: "we started off with the same initial condition(s) and the paths of the two planets diverged incredibly".

Phosphine gas on Venus presents us with a mystery then, and it directs our attention back to Venus. We don't have all the answers yet, and it might be the " glory of kings to seek [this] matter out." https://www.nbcnews.com/mach/science/nasa-has-plan-let-humanssoar-above-clouds-venus-ncna879851

https://www.sciencedirect.com/science/article/abs/pii/ S0019103509001328

https://www.nationalgeographic.com/science/2020/09/possible-signof-life-found-on-venus-phosphine-gas

https://www.nature.com/articles/s41550-020-1174-4

https://discourse.peacefulscience.org/t/_/11729/5

http://astrobiology.com/2020/09/on-the-possible-evolutionary-historyof-the-water-ocean-on-venus.html

http://cosmos.nautil.us/short/58/the-romantic-venus-we-never-knew

https://www.space.com/venus-runaway-greenhouse-effect-earthnext.html

https://biblehub.com/proverbs/25-2.htm 